framum

Sociológico

\section{Forum Sociológico}

Série II

$34 \mid 2019$

Habitação nas áreas urbanas de Lisboa e Porto: Da comunidade aos decisores políticos

\title{
Entre as práticas e as políticas. O Programa Habitar Porto
}

Between practices and policies. Programme Habitar Porto

Aitor Varea Oro, Ana Pinheiro e Mariana Almeida

\section{(2) OpenEdition}

\section{Journals}

Edição electrónica

URL: https://journals.openedition.org/sociologico/4820

DOI: $10.4000 /$ sociologico. 4820

ISSN: 2182-7427

Editora

CICS.NOVA - Centro Interdisciplinar de Ciências Sociais da Universidade Nova de Lisboa

Edição impressa

Paginação: 61-70

ISSN: 0872-8380

Refêrencia eletrónica

Aitor Varea Oro, Ana Pinheiro e Mariana Almeida, «Entre as práticas e as políticas. O Programa Habitar

Porto», Forum Sociológico [Online], 34 | 2019, posto online no dia 19 agosto 2019, consultado o 30 março 2022. URL: http://journals.openedition.org/sociologico/4820 ; DOI: https://doi.org/10.4000/ sociologico. 4820 


\title{
ENTRE AS PRÁTICAS E AS POLÍTICAS. O PROGRAMA HABITAR PORTO BETWEEN PRACTICES AND POLICIES. PROGRAMME HABITAR PORTO
}

\author{
Aitor Varea Oro, Ana Pinheiro e Mariana Almeida \\ Habitar Porto
}

\begin{abstract}
Resumo
O artigo toma por base o trabalho do programa Habitar Porto, um agente do terceiro setor que, para democratizar o acesso à produção de habitação, procura inserir as respostas criadas na sociedade civil dentro de um enquadramento institucional estável. Este passo do "coletivo" ao "público" permite tornar as soluções sustentáveis no tempo e acessíveis a uma maioria, mas obriga a um constante e difícil trabalho realizado entre o dentro e o fora das instituições. A partir da reflexão sobre o percurso do Habitar Porto nos últimos dois anos, perspetivado a partir do trabalho de autores que analisaram os processos de articulação e inovação social, o texto visará ilustrar de que maneira concreta acontecem estes processos e apontará para as oportunidades e resistências que devem ser objeto de reflexão para tornar estas iniciativas mais eficazes.
\end{abstract}

Palavras-chave: administração pública, sociedade civil, políticas de habitação, ilhas do Porto

\begin{abstract}
The article is based on the work of the programme Habitar Porto, a third sector agent that, in order to democratize access to housing production, seeks to insert the responses created in civil society within a stable institutional framework. This move from "collective" to "public" allows solutions to be sustainable over time and accessible to a majority, but it requires a constant and difficult work done between the inside and outside the institutions. Based on the reflection on the course of Habitar in the last two years, which will be framed on the work of authors who analyzed the processes of articulation and social innovation, the text will illustrate how these processes take place and will point out some opportunities and resistances that should be addressed in order to make these initiatives more effective.
\end{abstract}

Keywords: public administration, civil society, housing policies, Porto islands

\section{O problema da habitação}

Housing is seen as the domain of experts like developers, architects, or economists (...) but the crisis is deeper than that. We see housing in a wider perspective: as a political-economic problem. The residential is political - which is to say that the shape of the housing system is always the outcome of struggles between different groups and classes. (Madden \& Marcuse, 2016, p. 4)

Contexto atual. Como alargar os direitos sociais?

O acesso a uma habitação condigna é um direito consagrado pela Constituição portuguesa, tal como acontece com o direito a uma assistência sanitária universal e gratuita. Porém, dificilmente conseguiremos a efetivação do primeiro sem dotá-lo de infraestruturas semelhantes às que sustentam o segundo e da consciência pública que permite defendê-las.

Coloca-se então uma dúvida processual. Infraestruturas para dar resposta ao direito, ou consciência cidadã para defender a existência das mesmas? A pergunta sobre "por onde começar" para alterar (e articular) as respostas públicas ao dispor da sociedade é uma pergunta já clássica, perfeitamente sintetizada em palavras de Nuno Portas:

É uma típica questão de todas as fases de transição: a de saber por onde é que se começa. Se se começa pelos decretos e pelas 
leis ou se se começa por processos que alterem as condições e as relações de força, para que as leis sejam já a recolha dessas experiências e a sua necessária consolidação, no caso de serem boas e de a relação de forças ser favorável. (Portas, 1986, p. 637)

Um caso específico e umas perguntas mais abrangentes

$\mathrm{O}$ artigo toma por base o trabalho do Habitar Porto, uma iniciativa dinamizada por uma associação sem fins lucrativos que, partindo do pressuposto de que para diversificar o leque de beneficiários da habitação precisamos de diversificar o tipo de promotores, visa facilitar aos proprietários o acesso ao mundo profissionalizado da reabilitação urbana.

Pois que o Habitar não pretende apenas mostrar que fazer diferente é possível, mas também contribuir para que as respostas sejam sustentáveis no tempo e acessíveis a uma maioria suficiente; o programa trabalha com a convicção de que não há resposta satisfatória se ela não se insere dentro de um enquadramento institucional estável.

Este desejo de passar do "coletivo" ao "público" faz com que o Habitar trabalhe em articulação com diferentes níveis da Administração (Juntas de Freguesia [JF], Divisão Municipal de Urbanismo [DMU] e Instituto de Habitação e Reabilitação Urbana [IHRU]). As oportunidades e os constrangimentos deste caso específico permitem responder a questões mais abrangentes.

A partir da reflexão sobre o percurso do Habitar nos últimos dois anos, o texto visará perceber quais são os contributos da sociedade civil para a matéria em discussão, que oportunidades e resistências se identificaram, e que papel tem ou poderia ter o poder público para permitir a mudança de paradigma necessária na área da habitação.

\section{Tornar o problema público.}

\section{Breve enquadramento teórico}

"In an unequal society, the people who have the means to start projects are the elites. ' $\mathrm{No}^{\prime}$ is often the only thing that the relatively powerless are able to say that can be heard by those in power." (Madden \& Marcuse, 2016, p. 188)

\section{Do protesto à proposta}

Um dos fatores que mais se destacam no atual debate público é a pressão cidadã e mediática à volta da dificuldade de acesso a uma habitação condigna. Não é descabido afirmar que esta crise do alojamento é decorrente de um conjunto de medidas de liberalização do mercado de habitação, que tiveram o seu auge nos anos pós-troika.
Esta situação conduziu a um crescente descontentamento em que o perigo reside na descredibilização de instituições e setores profissionalizados e na sua substituição por formas de participação direta da sociedade civil que, em certas manifestações de voluntariado ou empreendedorismo, terminam por branquear a retirada do poder público.

Contudo, seria erróneo tentar deslegitimar este descontentamento. É necessário perceber as suas razões e canalizá-lo para a construção de soluções justas e eficazes, a fim de promover uma transformação das instituições tal que consiga abordar problemas que, na atual configuração do poder público, tem dificuldades em resolver.

\section{A harmonia dos elementos dissonantes}

O papel-chave que o Estado tem na criação das regras vigentes no campo da habitação é reconhecido por autores como Bourdieu (2000), que descreve como os atores com mais peso (empresas, fundos de investimento) tentam (e conseguem) influenciar o poder público para tornar as normas mais favoráveis às suas caraterísticas próprias e adquirir posições de vantagem.

Porém, isto não é o mesmo que produzir alterações tendentes para a inovação institucional, tarefa para a qual, como defende Cels (2012), a Administração Pública não está bem equipada. Segundo Granovetter (1973), os atores que habitam na periferia do sistema são os mais capazes para assumir riscos e espalhar a inovação a segmentos mais abrangentes.

Autores como Laclau (2005) ou Latour (2005) defendem que este tipo de transformações requer re-ensamblar um conjunto a partir dos seus fragmentos, juntando demandas que antes estavam isoladas entre si. E isto exige refletir sobre alguns atores-chave com base nas suas identidades e regras, próprias ou atribuídas, que constroem para si entendimentos muito diferentes do problema.

Um ator (fr)ágil. Técnicas para a re-ensamblagem social $^{1}$

É neste contexto que se enquadra a ação do Habitar, que pretende resolver as necessidades de alojamento dos inquilinos cuidando dos interesses dos proprietários, mobilizando financiamento disponível para reabilitação urbana a custos controlados e criando, com isto, trabalho qualificado para os profissionais. $^{2}$

Surgida da sociedade civil, a iniciativa tem no seu pouco peso institucional e na dificuldade para definir, de maneira consensual, a sua missão ("promover uma transformação social a partir da habitação") a sua maior força e a sua maior fraqueza, motivos pelos quais o programa se esforça 
por definir novos termos para o debate, balizando a sua ação a partir de três princípios:

- Encontrar fontes de legitimidade que sejam capazes de congregar maiorias sociais abrangentes. Por exemplo, falar em "direito à cidade" ou no processo "SAAL" atrai segmentos muito reduzidos da sociedade. Porém, falar em "habitação a preço justo" ou fazer um paralelo entre a habitação e a saúde mobiliza um conjunto mais alargado de atores, que é o essencial para poder trabalhar.

- Invocar agentes que normalmente não participam da discussão ou que o fazem com base em identidades atribuídas por terceiros. Utilizar os espaços de socialização como fóruns privilegiados de debate (em vez dos formatos técnicos ou académicos) ou definir os proprietários (em vez dos inquilinos) como a principal massa crítica a mobilizar para promover habitação a custos controlados contribui para colocar o problema na agenda pública de uma maneira mais eficaz, criativa e inclusiva, ultrapassando falsos dilemas.

- Criar espaços onde as coisas se possam fazer e dizer de outra maneira. A ação dentro dos moldes de cada um dos atores-chave (técnicos, inquilinos, proprietários, instituições) impõe uns limites ao debate que, por vezes, só é possível ultrapassar criando áreas de interação entre parte destes atores, onde a falta de regras estabelecidas seja colmatada pelo bom senso, potenciando assim as pontes em vez dos muros.

Ao longo das próximas duas epígrafes, vamos pormenorizar a maneira específica como o Habitar tem tentado promover uma formulação diferente dos problemas, capaz de identificar curto-circuitos no atual funcionamento do sistema, formular outra geografia para os problemas, atrair parceiros capazes de materializar soluções alternativas e promover um enquadramento institucional estável para as mesmas.

\section{Nada nasce com a sua própria forma. Cronologia do programa}

O Habitar inicia a sua atividade em abril de 2016, com base nos princípios referidos e ao abrigo de um protocolo com a Junta de Freguesia do Bonfim (JFB), considerado o ator essencial para outorgar legitimidade à iniciativa e ancorá-la à realidade do terreno. Enquadrada numa lógica de recursos escassos, esta aliança dura até à atualidade com benefícios mútuos para ambas as partes.

A parceria formalizou-se com o formato de um gabinete de atendimento técnico, uma prática tipificada que podia ser aceite pela administração pública e que permitia ao Habitar auscultar as necessidades da população numa lógica de proximidade. Com o objetivo de exponenciar tanto os benefícios do formato como o abrigo institucional, desenvolveram-se duas estratégias:

- Por um lado, o recurso à comunicação social, divulgando o problema em termos simples e inclusivos, o que serviu para atrair o maior número possível de utentes ao gabinete, exponenciando aquilo que estava ao abrigo do protocolo. O discurso lançado, que permanece inalterado, foi o seguinte: os problemas de um proprietário que não pode reabilitar a sua propriedade, de um inquilino que não encontra habitação com rendas acessíveis e de um profissional da construção que não encontra trabalho ou que gostaria de desenvolvê-lo dentro de outros moldes não são três problemas separados, mas três sintomas do mesmo problema: as ferramentas existentes para a promoção da cidade não alcançam uma maioria social (e, portanto, devem ser democratizadas).

- Por outro lado, o aproveitamento do abrigo institucional e mediático para alargar a rede e desenvolver práticas que, sendo essenciais para a construção social do problema, não cabiam nos desígnios consagrados pelo protocolo inicial. O objetivo era crescer em capacidade operacional, não tanto a partir da afinidade ideológica ou setorial, mas sim a partir de práticas concretas que mobilizassem interesses de parceiros estratégicos que estariam disponíveis para trabalhar, alargando as áreas de influência do programa. Desta maneira foi possível ir construindo um domínio de interesses sobre os quais valia a pena trabalhar e que, embora não conduzissem à construção imediata de habitação, faziam parte da construção de uma solução mais sustentável no longo prazo.

\section{Práticas emergentes}

A duração do primeiro protocolo do Habitar foi de 6 meses, insuficientes para realizar projetos de arquitetura, menos ainda para materializá-los, com as agravantes de que o único programa existente na altura era o Reabilitar para Arrendar (RpA) e de que a dificuldade não residia apenas no encaminhamento para os programas, mas, acima de tudo, no acompanhamento dentro dos mesmos.

Neste sentido, cabe ressalvar uma primeira dificuldade estruturante: a dificuldade de entregar projetos de arquitetura a gabinetes privados a partir de uma estrutura que, sendo do terceiro setor, trabaIha ao abrigo do poder público. É esta uma questão de difícil resposta, cuja solução estará condicionada a um reposicionamento dos atores compatível com 
as reorganizações possíveis dos campos simbólico e burocrático.

A consciência de precisar de mais margem para resolver estes problemas estruturantes fez com que este tempo fosse utilizado para desenvolver um conjunto de práticas que, fora da parceria inicial com a JFB, mas sem objeção da mesma, permitiram alargar o conjunto de parceiros interessados em prorrogar o protocolo e alterar o seu conteúdo. Podemos elencar brevemente um conjunto de princípios e estratégias utilizadas.

1. A proximidade como regra. O abrigo da JFB permitiu que equipas mistas de arquitetos e de educadoras sociais visitasse as casas dos utentes do Gabinete de Ação Social para realizar avaliações físicas e sociais. Mesmo sem expectativas de intervenção, auscultar o terreno foi importante para conhecer as carências e desenvolver uma gramática comum às duas disciplinas, evitando que os arquitetos se tornassem educadores sociais e vice-versa.

2. Desenvolvimento de estratégias coletivas. Os atendimentos no gabinete revelavam que, em certas ocasiões, um problema individual só podia ser resolvido a partir de uma solução coletiva. Esta circunstância, que decorre das exigências dos programas públicos existentes ou, face à sua ausência, da necessidade de adquirir uma posição de maior força perante os atores dominantes do mercado, pode ser explicada com dois exemplos:

a) O pedido de uma utente de resolver a falta de uma instalação sanitária na sua casa não podia resolver-se a partir dos programas existentes, que exigiam a reabilitação integral do edificado, neste caso, toda a "ilha". Assim, foi necessário trabalhar com a totalidade dos moradores para perceber a sua recetividade para propor aos proprietários uma candidatura ao RpA, bem como a sua capacidade de atualizar a renda, com o intuito de permitir financiar as obras e garantir a manutenção futura.

b) O inflacionamento dos preços no Bonfim, visível a partir de 2016, fez com que um grande número de famílias que desejava viver na freguesia não pudesse concorrer com os grandes agentes do mercado. Perante esta situação, resolveu-se unir os vários pedidos recebidos no gabinete e passar do individual ao coletivo. A desadequação e o desinteresse das estruturas cooperativas tradicionais evidenciaram a necessidade de desenvolver novas estruturas produtivas mais permeáveis ao contexto socioeconómico atual.
3. Dimensão formativa. Um dos melhores exemplos do que se quer dizer com "promover uma transformação social a partir da habitação" é a acumulação de experiência, a produção e transmissão de conhecimento, especialmente criando novas redes que permitam ultrapassar os constrangimentos das atuais estruturas produtivas (que materializam as encomendas) e de mediação (que Ihes dão forma). Este tipo de práticas exige a participação de entidades com capital social, simbólico e de conhecimento, e podem ser ilustrados com dois exemplos:

a) Formação de equipas técnicas. Apesar de serem públicos muito diferentes, rapidamente se percebeu que proprietários, inquilinos ou, inclusivamente, instituições do terceiro setor com interesse em matéria de habitação acessível tinham pedidos recorrentes que poderiam ser um fator aglutinador: mão de obra qualificada não especulativa. Graças à mediação da junta, organizaram-se iniciativas que visavam qualificar os utentes do CICCOPN em formação prática em contexto de trabalho.

b) Alargar o campo da boa arquitetura. Em 2017, a empresa de gesso cartonado Pladur organizou o seu $27 .{ }^{\circ}$ concurso ibérico de arquitetura, que congrega anualmente dezenas de faculdades de Espanha e Portugal. Para evitar uma romantização do problema das "ilhas" (que foi o caso de estudo proposto naquela edição), iniciou-se uma parceria que visou utilizar as faculdades como meio de difusão de umas bases que convidavam a pensar na realidade socioeconómica da ilha como ferramenta de projeto e o prémio como uma maneira de incitar este tipo de abordagem disciplinar.

Do terreno aos terrenos

Em março de 2017 o programa é alargado em duas direções: por um lado, no âmbito territorial (a Junta Freguesia de Campanhã [JFC] junta-se à rede de parceiros); por outro, no âmbito administrativo, onde se começa a explorar o espaço "entre" na relação das JFB e JFC e a DMU. Esta situação permite multiplicar a permeabilidade entre instituições e território:

- Em primeiro lugar, porque a entrada de uma nova junta torna necessária a realização de um novo protocolo - o que permite incorporar de maneira oficial algumas das práticas marginais desenvolvidas à margem do protocolo durante a primeira fase. O facto de essa junta e essa freguesia terem diferentes 
caraterísticas da do Bonfim permitiu que a leitura do protocolo fosse distinta em cada território, possibilitando ensaiar diferentes soluções e replicá-las quando bem-sucedidas.

- Em segundo lugar, porque o protocolo, tripartido, envolve a DMU. A entrada de um novo nível da Administração traz, como consequência, uma oportunidade - acresce uma camada técnica que não possuíam nem as juntas nem o Habitar - e um desafio conciliar linguagens e prioridades por vezes contraditórias, ainda que dentro do mesmo município.

Esta nova fase serviu para identificar um segundo problema estruturante: às vezes o problema não é cumprir os regulamentos (dos programas de financiamento ou dos projetos necessários para usufruir deles), mas sim as burocracias associadas (sendo estas, por vezes, um fator de exclusão dos cidadãos com menos competência técnica ou poder para adquiri-la).

\section{Práticas consolidadas}

Segundo o sociólogo Tomás R. Villasante (1989), existem três principais maneiras de articular as redes sociais: a "populista" (confluência da Administração com os Grupos Informais), a "ciudadanista" (confluência dos Grupos Formais e dos Grupos Informais) e a "gestionista" (confluência dos Grupos Formais e da Administração).

Com a assinatura do segundo protocolo e, incrementalmente (especialmente a partir das autárquicas de 2017), o Habitar começa a desenvolver uma prática ancorada no último grupo. Esta escolha não depende tanto da vontade (considera-se mais interessante a "ciudadanista") mas antes da necessidade objetiva, que pode sintetizar-se nas seguintes razões:

- Por um lado, considera-se o trabalho "no terreno" importante, mas a escuta de proximidade pode dar-se também em "outros terrenos" que são fulcrais para o cumprimento dos objetivos, como pode ser o campo burocrático (onde não faltam pessoas interessadas em mudar as práticas habituais).

- Por outro lado, chega-se à conclusão de que os proprietários com quem se trabalha (e, por extensão, os inquilinos) não desejam ativistas, mas antes projetos aprovados. Isto faz com que se sinta a necessidade de especializar e profissionalizar progressivamente o nosso trabalho.

- Além disso, começa-se a perceber que a dicotomia "ativistas" e "tecnocratas" é redutora. Interessa desenvolver uma atividade que ultrapasse os dois extremos, incorporando as razões que Ihes são subjacentes. Esta hipótese só é compatível com a profissionalização quando se está de maneira ativa nos vários terrenos.

Assim, decide-se deixar cair certas parcerias e incorporar o seu conteúdo em práticas vinculadas e veiculadas por atores institucionais com os quais seria possível traduzir as preocupações individuais para uma gramática comum que, quando materializada, poderá cristalizar em soluções mais eficazes e acessíveis a uma maioria.

Fatores externos, de natureza especialmente política, fazem com que o foco de ação comece a afunilar-se no caso específico das ilhas. A situação de emergência em que vivem estas populações e a incapacidade manifesta de dar resposta a todas as frentes faz com que se decida focar os contributos nesta frente.

As práticas descritas em seguida são consequência lógica do que foi descrito:

1. Arquitetos de família: Regulamentada por um contrato interadministrativo, com duração de dois anos, sem trocas económicas, entre a FAUP, a JFB e o Habitar. Esta iniciativa, que visa intervencionar situações agudas em casas de ilha, dá estabilidade, legitimidade e recursos a uma parceria informal desenvolvida previamente entre o Habitar (que proporcionava apoio técnico em forma de estudo prévio realizado pelos estagiários) e a JFC (que sinalizava os beneficiários e disponibilizava os recursos para as intervenções).

Este programa visa atingir três objetivos. Os dois primeiros são óbvios: dar melhores respostas aos beneficiários e ampliar a formação dos estudantes. O terceiro é mais estratégico: qualificar as intervenções do programa Casa Reparada Vida Melhorada (CRVM) (comum às duas JF e responsável pelas intervenções) criando uma ponte entre as prioridades da JF (o urgente: mitigar as penosas condições de vida dos fregueses em exclusão social) e as da CMP (o importante: garantir que as intervenções se enquadrem nos direitos urbanísticos e construtivos dos habitantes).

2. Diagnóstico socioespacial de 40 ilhas na ARU de Campanhã-Estação: Contrato público, entre a DMU e o Habitar, com duração de dois anos e com dotação orçamental que possibilita manter a presença nos terrenos. Este trabalho visa "conhecer e compreender as pessoas que habitam estes núcleos, nomeadamente a sua relação com a habitação, com o núcleo e com a envolvente, bem como as suas expectativas", e levantar 
"as estruturas edificadas, por forma a ser possível definir estratégias de intervenção, bem como a quantificação e avaliação dos custos das intervenções". ${ }^{3}$

O trabalho envolve um intenso trabalho de campo e um rigoroso tratamento de informação, com recurso a Sistemas de Informação Geográfica. Além dos objetivos descritos, este estudo tem duas valências estratégicas: por um lado, facilita a comunicação entre os diferentes níveis da administração local (grande parte da metodologia assenta nas aprendizagens na proximidade ensaiada no trabalho com a junta); por outro, consolida uma metodologia de análise territorial e de sistematização e produção incremental de informação de malha fina.

3. Concurso Pensar, Construir, Habitar. Iniciativa regulamentada por protocolos pontuais entre a JFC e o Habitar, que pretende fazer a ponte entre o património degradado e os programas públicos de reabilitação com foco nas rendas acessíveis. Esta prática, cuja segunda edição está a ser delineada no momento de escrita deste texto, pretende resolver as necessidades dos inquilinos cuidando dos interesses dos proprietários através de um processo aberto, transparente, onde os projetos são adjudicados com base em critérios de adequação.

O concurso configura uma plataforma que integra várias entidades públicas, com o objetivo de que entre concorrentes e proprietário não exista um simples caderno de encargos, mas antes uma ideia de cidade, o que divulga novas práticas entre os concorrentes. A primeira edição serviu para constatar que era possível mudar práticas (a DMU definiu critérios de apreciação das "ilhas", entidades morfológicas que não encaixam no PDM mas que encontram abrigo legal no RJUE, RJRU e RERU) ou testar programas (o IHRU utilizou as propostas para testar o programa 1.0 Direito).

Identifica-se assim um terceiro problema estruturante: articular diferentes demandas (proprietários, inquilinos e instituições) é possível de maneira pontual. Mas fazer isto de maneira sustentada e incluindo, aliás, critérios multissetoriais (como por exemplo emprego ou saúde) requer inserir as ações num enquadramento institucional estável. Passamos, assim, do reino das práticas ao reino das políticas.

Figura $1 \triangleright$ Presença do Habitar nos diferentes terrenos
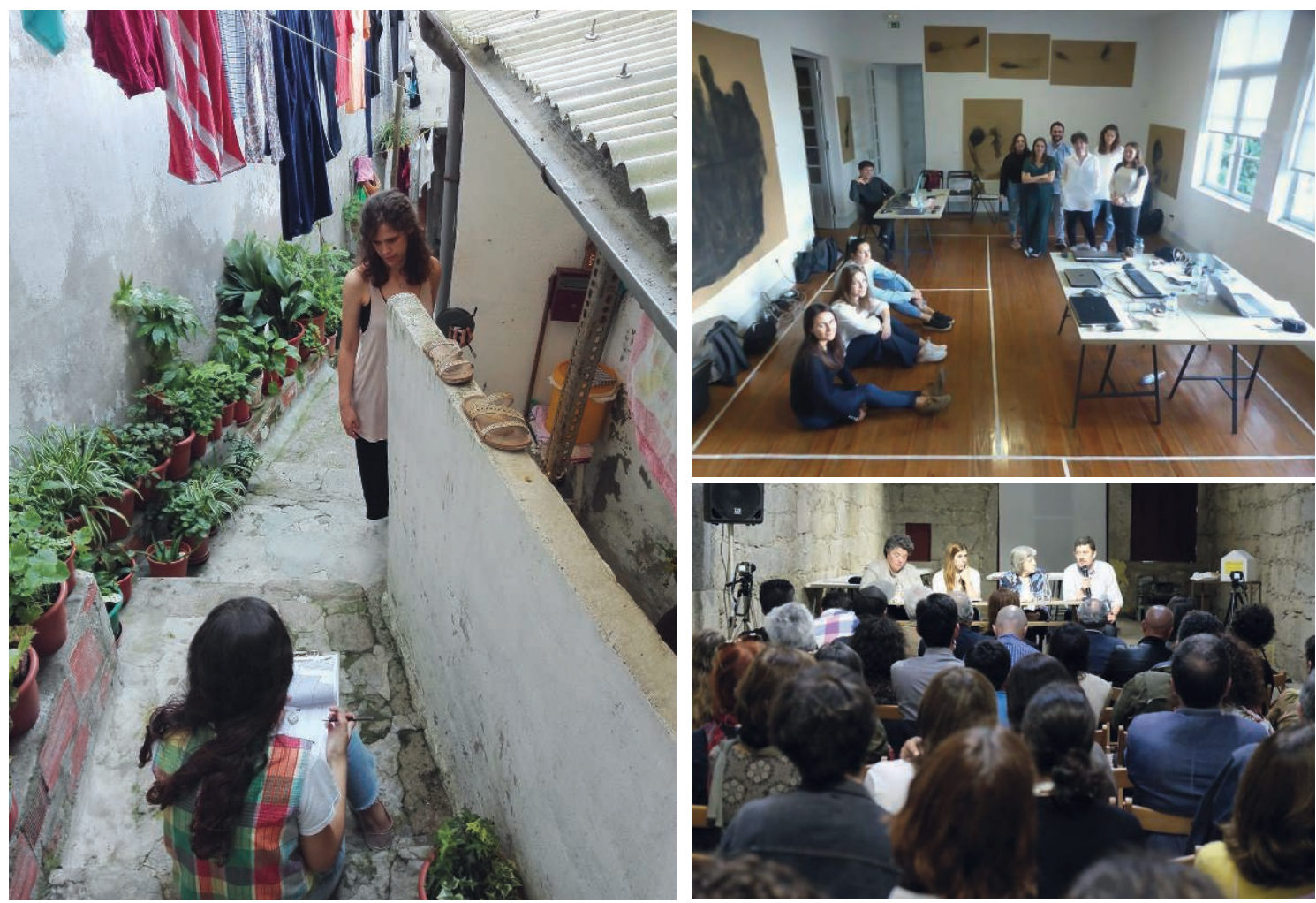

Fonte: Conjunto de imagens de autoria de Ana Pinheiro, Marta Paquete e Mira Fórum 
Figura $2 \triangleright$ Propostas de reabilitação de ilhas alavancadas pelas práticas do Habitar
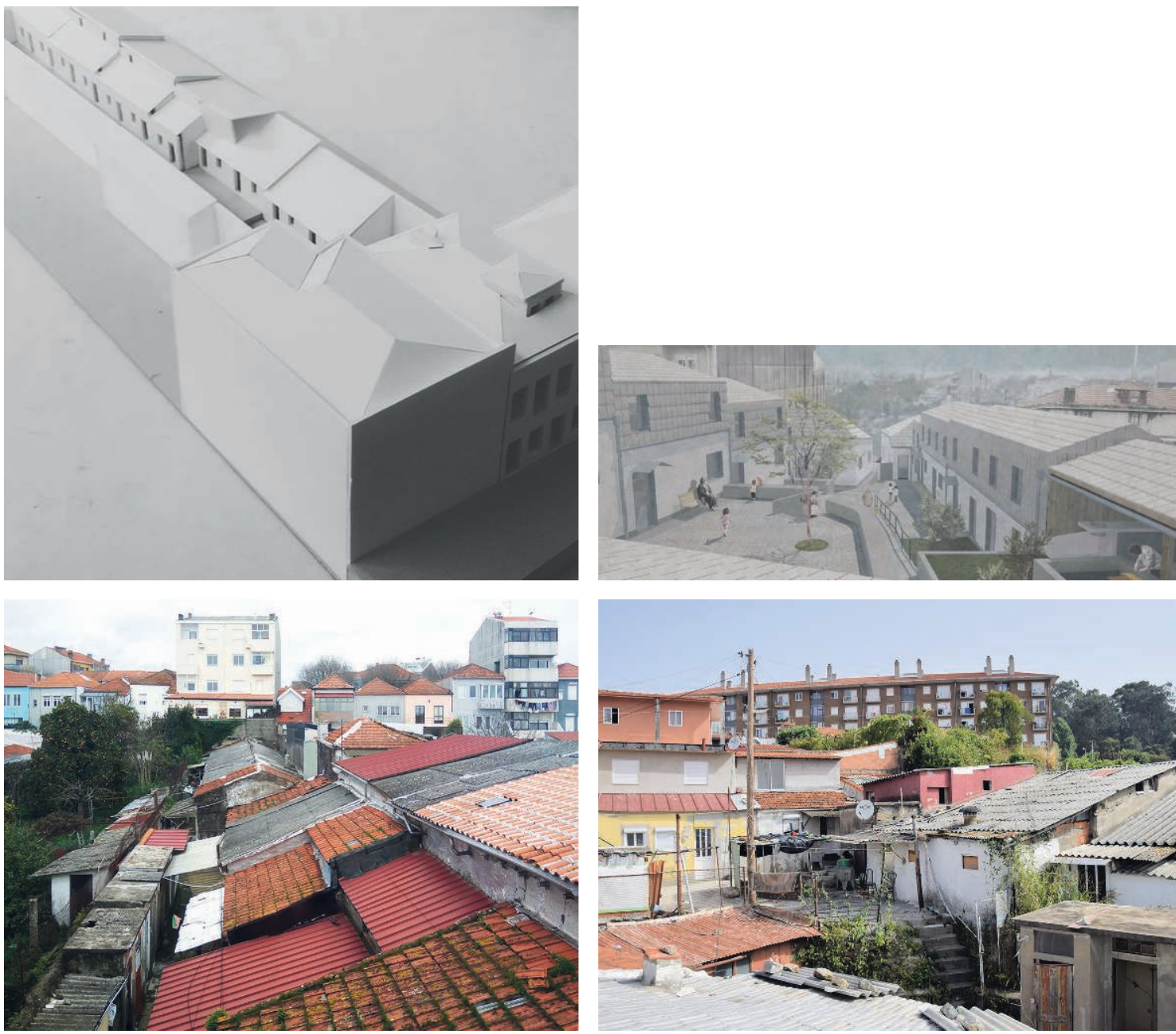

Fonte: Conjunto de imagens de autoria de Aitor Varea Oro, Merooficina, Bernardo Amaral e Tiago Delgado

\section{Das práticas às políticas}

By a successful innovation process we basically mean, first, a changed practice - a clear and tangible change from the way things were done in the past, and second, operational capacity to sustain the innovation as well as continued support from crucial stakeholders for the innovation. (Cels \& Nauta, 2012, p. 5)

Construir a forma da solução. Primeiros passos no Porto

No momento de escrita destas linhas, os responsáveis do Habitar e o Município do Porto chegaram a um acordo para expandir parte do programa, criando uma estrutura que preste apoio aos proprietários de "ilhas" nas freguesias do Bonfim e de Campanhã, articulando as práticas de todos os atores envolvidos e acumulando e transmitindo conhecimento para uma ação mais eficaz dos técnicos. ${ }^{4}$

Desta maneira, cria-se uma ponte entre os desígnios do Plano Estratégico de Desenvolvimento Urbano (PEDU) do Porto (criar novas ferramentas para permitir aos privados a dinamização do seu património) e as ferramentas criadas pelo Governo Central a partir da Nova Geração de Políticas de Habitação (NGPH) (nomeadamente, o programa 1.0 Direito). Esta ponte passa por reconhecer a necessidade de acompanhar os proprietários no processo de requalificação, aumentando o parque de habitação acessível no município.

Na base desta inovação, que consolidará as práticas identificadas pelo Habitar a partir de um contrato de cooperação por três anos entre o município e a FAUP (que faz parte da rede de parceiros criada), jaz um intenso trabalho de re-ensamblagem social, que tem por base uma atribuição diferente 
de papéis e um novo discurso à volta do problema das ilhas.

Importa destacar que, nesta tarefa de produção de sentido, não basta criar novos termos de debate. É imprescindível obter o consentimento de certos atores-chave que, por causa do seu prestígio e capital simbólico, legitimam as ideias lançadas. Para chegar a estes agentes, é imprescindível pensar em termos de práticas, atores e ações fora dos espaços consolidados.

Estes atores podem ser muito divergentes entre eles, falar para vários públicos e utilizar meios de expressão diferentes. De facto, é essencial que assim seja para que estas novas ideias ocupem o lugar do "bom senso". É possível dar alguns exemplos deste ascenso por capilaridade desde as necessidades sentidas no terreno até à sua entrada nas instituições:

- Em fevereiro de 2018, dois anos depois do lançamento do programa, o presidente da Câmara do Porto, em sede de audição parlamentar na Assembleia da República, afirmou que, através do Habitar, a cooperação entre Juntas e DMU persegue "trabalhar na capacitação técnica dos projetistas" e que se pretende "a partir das práticas concretas, desenhar políticas (...)".

- Em agosto de 2018, o jornal Porto, distribuído gratuitamente a todos os munícipes, afirma que o Habitar pretende:

"Simplificar ao máximo o processo de requalificação (com recurso a parcerias institucionais no apoio à obra), de modo a que os proprietários se sintam motivados a disponibilizar habitação a rendas acessíveis." (Finalmente descobriu-se o caminho para as ilhas, 2018.)

- Em outubro de 2018, o Jornal dos Arquitectos, distribuído gratuitamente a todos os membros da Ordem dos Arquitectos, destaca que o Habitar:

"... promovendo mecanismos de consulta de profissionais da arquitetura através do concurso de ideias e de diálogo, reforça o contributo dos proprietários privados para pensar as políticas públicas de habitação e ensaia coletivamente o desenho de soluções" (Oliveira, 2018).

Prever a forma dos problemas. Desafios e ferramentas a explorar

A solução descrita no ponto anterior cria uma resposta útil e pública à requalificação das ilhas, integrando, em simultâneo, parte das práticas perseguidas pelo Habitar desde o início da sua atividade (dando uma nova expressão, mais alargada, aos processos formativos). Contudo, o sucesso do programa estará condicionado a dois desafios que terão de ser resolvidos em simultâneo:

- Por um lado, a pressão social que, necessariamente, surgirá como resultado de uma prática que, inevitavelmente, não constituirá, por si só, uma resposta ao problema da habitação (porque o programa estará focado apenas nas ilhas, deixando fora outras tipologias e segmentos sociais; porque o problema é multissetorial, e não cingido unicamente à habitação, etc., ...).

- Por outro lado, a margem de ação para responder às contingências. A iniciativa nasceu ancorada na sociedade civil, mas cresceu articulando-se com os agentes institucionais. A sua formalização, que se traduz num contrato com direitos e obrigações para as duas partes, deixará inevitavelmente lacunas difíceis de contornar.

Aguardamos o desenvolvimento do futuro programa para perceber se os constrangimentos identificados podem ser atenuados pelo facto de a entidade promotora ser, nesta nova fase, uma entidade pública capaz de mobilizar outro tipo de articulações, discursos e legitimidades.

\section{Conclusão: regresso ao público}

A habitação não contribuirá para um desenvolvimento social equitativo se a sua promoção não for impulsionada institucionalmente e articulada com o resto de políticas públicas.

Ao longo do texto temos tentado ilustrar de que maneira esta ação pode ser progressiva, deve outorgar protagonismos aos vários níveis da administração e precisa, por vezes, de catalisadores externos. Estas espoletas, pertencentes à sociedade civil, têm menor peso do que as instituições (o que as impede de sustentar as ações), mas possuem mais agilidade (que as coloca em posição mais favorável para identificar e propor iniciativas mais próximas das dinâmicas locais reais).

Neste sentido, a principal conclusão é que a estratégia do Habitar prova que para implementar uma solução técnica nova é precisa a criação prévia de um novo espaço técnico e político, e que este novo espaço surge com o objetivo de articular um conjunto de demandas que eram não só heterogéneas, mas, acima de tudo, provenientes de atores anteriormente antagónicos. A grande dificuldade reside em institucionalizar estas práticas sem perder a conexão com o território.

Como viabilizar que o passo das práticas às políticas seja um salto e não um passo atrás? Tentaremos dar resposta da maneira mais pragmática possível referindo, por um lado, as ferramentas que já existem no atual quadro legislativo e, por outro, 
os princípios que, retirados da nossa experiência, podem tornar mais robusta a sua implementação.

a) Ferramentas existentes ou previstas na NGPH úteis para permitir a permeabilidade entre sociedade civil e poder público

Os desafios identificados parecem apontar a necessidade de capacitar o debate cidadão e de pôr as instituições ao serviço da cidadania. Parece importante aproveitar os espaços abertos pela NGPH e colmatar algumas das suas lacunas. O impacto das políticas de habitação nas populações é diretamente proporcional a três fatores:

- Por um lado, a produção e transmissão de informação de qualidade, transparente e acessível a cidadãos, investigadores, comunicação social e decisores políticos. É um passo incontornável para qualificar o debate público, balizar os termos da discussão e canalizar o descontentamento para ações produtivas. O programa Porta ao Lado parece incidir em alguma destas dimensões e seria positivo que a informação e o público-alvo fossem mais abrangentes.

- Por outro lado, o envolvimento da cidadania na promoção do espaço urbano, tanto nas dimensões que foram referidas neste texto como na produção de informação de qualidade, assente em lógicas de proximidade ou de participação. O programa Da Habitação ao Habitat parece ir nesta direção, embora pensemos que este tipo de estratégias não deve ficar cingido aos territórios marginais.

- Finalmente, é essencial articular a habitação com o resto das políticas públicas. As Estratégias Locais de Habitação parecem uma boa estratégia para passar das práticas isoladas às políticas integradas. Mas para isto é necessário continuar a tarefa de re-ensamblagem social descrita neste artigo, com o intuito de contornar a habilidade que o statu quo tem para neutralizar toda a tentativa de alteração.

b) Quais os rumos que podem guiar a NGPH para ultrapassar as resistências existentes

É muito difícil que se avance sem maior investimento do Estado, mas é impossível que o sentido do progresso esteja em relação direta com a sociedade para a qual se trabalha se não se envolvem os vários níveis da Administração e se não se utilizam todas as ferramentas para ancorar as políticas na cidadania. Neste sentido destacamos:

- É essencial o passo da ação coletiva à articulação pública, que permite desde a criação de novas instituições (como o programa de apoio aos proprietários das ilhas) até ao uso das mesmas com um uso comunicativo e não tanto punitivo ${ }^{5}$ (exponenciando assim a criação de novas "reputações" ensaiadas nas práticas consolidadas como Arquitetos de Família ou o concurso Pensar, Construir, Habitar).

- É fulcral a democratização da habitação: primeiro, da oferta e procura (como já se referiu, diversificar o leque de beneficiários da habitação através do estabelecimento de novos promotores); segundo, dos objetivos da reabilitação; e terceiro, dos termos da discussão. Falamos de uma relação dialética: é preciso aproximar as instituições das populações e é preciso aproximar as populações das instituições.

Em segundo lugar, é necessário afinar a arquitetura institucional. Como se tratou de provar ao longo do texto, as instituições têm tanto poder para implementar este tipo de inovações como constrangimentos para o fazer. Nesta circunstância, os atores com mais liberdade de ação podem estar nos vários terrenos e facilitar a permeabilidade entre atores. Perante este cenário, identificamos duas possíveis linhas de ação:

- Lutar contra as resistências que impedem que os agentes externos à Administração possam realizar o trabalho que Ihes cabe. Embora estas resistências sejam de todo o tipo (de recursos, contratuais, da própria cultura do terceiro setor), cingir-nos-emos a uma única: é necessário conseguir medir o impacto das práticas alternativas. Como afirmam Cels et al., (2012, p. 7), "the absence of such mechanism gives established organizations or practices in the public sector much more power to actively resist destruction in their fight for survival".

- Perceber que parte do trabalho a realizar pelas instituições está orientada não tanto para a construção de resultados, mas, antes, para a definição das estruturas em que os vários agentes se vão relacionar. Se é verdade, como parece afirmar a experiência, que a institucionalização das práticas emergentes envolve sempre o risco de colocá-las numa redoma, talvez seja necessário que o próprio poder público desenvolva regras e dinâmicas específicas que permitam a sobrevivência dos ecossistemas onde é possível dialogar entre o dentro e o fora do poder instituído.

A arquitetura é uma prática de caráter nitidamente coletivo. As pessoas sempre se juntaram para resolver os seus problemas em matéria de habitação e continuarão a fazê-lo. As fórmulas serão 
basicamente as mesmas: os tradicionais GTL ou as cooperativas de habitação encontram continuidade no gabinete de atendimento do Habitar e nas suas estratégias colaborativas.

O que muda é a maneira como se articulam os atores.

Cabe-nos trabalhar na criação de condições apropriadas para que as instituições sejam a garantia da estabilidade e da universalidade de acesso às soluções, da maneira mais apropriada para a natureza de cada território. A intervenção da sociedade civil é sempre desejável e necessária, mas pensamos que será um bom passo em frente tornar esta participação não apenas mais frequente como, principalmente, mais sustentável.

\section{Notas}

1 Uma aproximação mais pormenorizada ao trabalho do Habitar enquanto trabalho de ensamblagem social pode ser encontrado em Varea Oro \& Travasso (2018).

2 No momento de escrita destas linhas, o Habitar trabalha em quatro casos em diferentes fases (licenciamento, projeto de execução ou estudo prévio). Estas operações pretendem mobilizar cerca de $1100000 €$ de investimento público.

3 Extraído do contrato público entre o Município do Porto e o Habitar Porto.

4 Ver Varea Oro \& Vieira (2018).

5 Conceito retirado de Cortina (2017).

\section{Referências bibliográficas}

Bourdieu, P. (2000). Les structures sociales de I'economie. Paris: Seuil.

Cels, S., Jong, J., \& Nauta, F. (2012). Agents of change: Strategy and tactics for social innovation. Washington, D.C.: Brookings Institution Press.
Cortina, A. (2017). Aporofobia, el rechazo al pobre - Un desafío para la democracia. Barcelona: Ediciones Paidós.

Finalmente descobriu-se o caminho para as ilhas (2018, agosto). Porto, Retirado de http://www. porto.pt/assets/misc/img/noticias/Jornal\%20 Porto./Numero\%207/Jornal\%20Porto.\%20 n. \%C2\%BA\%207\%20-\%20Vers\%C3\%A30\%20 web.pdf

Granovetter, M. (1973). The Strength of Weak Ties. American Journal of Sociology, 78(6), 1360-1380.

Laclau, E. (2005). La razón populista. Buenos Aires/ México: FCE.

Latour, B. (2005). From realpolitik to dingpolitik or: How to make things public. In: B. Latour \& P. Weibel (Eds.), Making things public: Atmospheres and democracy (pp. 14-41). Cambridge, M.A.: MIT Press.

Madden, D., \& Marcuse, P. (2016). In Defense of housing. The Politics of Crisis. Londres: Verso.

Oliveira, I. (2018). O Futuro das Ilhas do Porto. Jornal Arquitectos. Retirado de http://www.jornalarquitectos.pt/pt/jornal/epicentros-pos-industriais/o-futuro-das-ilhas-do-porto

Portas, N. (1986). O processo SAAL: entre o Estado e o poder local. Revista Crítica de Ciências Sociais, 18/19/20, 635-644.

Varea Oro, A., \& Travasso, N. (2018). Assembling alternative practices: pushing the development of a new housing programme in Porto (Portugal). 8th International Conference on Building Resilience ICBR.

Varea Oro, A., \& Vieira, P. (2018). Programa Ponte. Uma abordagem sustentada às ilhas do Porto. Porto: PNUM proceedings.

Villasante, T. R. (1989). Retrato de Chabolista com piso: Análisis de redes sociales en la remodelación de barrios de Madrid. Madrid: Alfoz-CIDUR.

\section{(i)}

Recebido a 31/10/2018. Aceite para publicação a 04/02/2019

Aitor Varea Oro (aitorvarea@gmail.com). Habitar Porto. Rua Alves Redol, 407, 2.0 Dt.0, 4050-043 Porto.

Ana Pinheiro (anaacpinheiro@hotmail.com). Habitar Porto. Rua Alves Redol, 407, 2.0 Dt.0, 4050-043 Porto. Mariana Almeida (mariana.ribeiro.almeida@gmail.com). Habitar Porto. Rua Alves Redol, 407, 2.0 Dt. ${ }^{\circ}$ 4050-043 Porto. 